\title{
CORRELATION DEVELOPMENT FOR EROSIVE WEAR RATE ON PELTON TURBINE BUCKETS
}

\author{
ROBIN THAKUR ${ }^{1}$, ANIL KUMAR ${ }^{2}$, SOURABH KHURANA $^{3} \&$ MUNEESH SETHI $^{4}$ \\ ${ }^{1,2}$ School of Mechanical \& Civil Engineering, Bajhol, Solan, (HP), India \\ ${ }^{2}$ Department of Mechanical Engineering, OM Institute of Technology, Juglan, (Hisar), India \\ ${ }^{3}$ School of Engineering \& Technology, AP Goyal Shimla University, Shimla, (HP), India

\begin{abstract}
The overall performance of the hydro turbine decreases with the increase in the erosive wear. Erosive wear of hydro power turbine components depends on various parameters such as silt concentration, silt size stream velocity and working time. In the current study, an experiment was carried out with Pelton turbine in actual flow conditions to investigate the outcome of silt size and silt concentration on the erosive wear of the Pelton turbine bucket. Examinations have been performed by the specimen of silt, gathered from Chamera Lake in Himachal Pradesh. The silt size varied from 90 to $450 \mu \mathrm{m}$, generally silt concentration fluctuated from 2000 to $8000 \mathrm{ppm}$, stream velocity differed from 25.4 to 27.3 $\mathrm{m} / \mathrm{s}$ and working time was 8 hours. In light of exploratory information, correlation has been produced as far as normalized wear $(W)$ as a component of silt parameters and working parameters. Maximum erosion in Pelton bucket was observed on the splitter and some part of notch, and this result was a comparison with Finite Element Analysis simulation. Correlations for the erosive wear rate with operating parameters have been developed. The correlation established in this review can be utilized to anticipate the normalized wear with an error of \pm 12 . $8 \%$.

KEYWORDS: Hydro Turbine, Renewable Energy, Silt Size, Erosion \& Stream Velocity
\end{abstract}

Received: Apr 18, 2017; Accepted: May 15, 2017; Published: Jun 06, 2017; Paper Id.: IJMPERDJUN201727

\section{INTRODUCTION}

Renewable technologies are considered as clean sources of energy, and optimal use of these resources are to minimize environmental impacts, produce minimum secondary wastes, and these are sustainable based on current and future economic and societal needs. A renewable energy source can be defined as a simple, sustainable resource available over the long term at a reasonable cost that can be used for any task without negative effects [1-2]. Renewable energy sources include both direct solar radiation by collectors and indirect solar energy such as wind, hydropower, ocean energy and biomass resources that can be managed in a sustainable manner [2-4]. Positive points in the use of renewable energy sources are; increased diversity in energy supply options, both for developed and developing countries, less dependence on fossil fuels, the increase of net employment, the creation of export markets and a reduction in greenhouse gas emissions and climate change [5-6]. Renewable energy supplies $18 \%$ of the world's final energy consumption counting traditional biomass, large hydropower, and "new" renewable (small hydro, modern biomass, wind, solar, geothermal, and biofuels). Traditional biomass, primarily for cooking and heating, represent about $13 \%$ and is growing slowly in some regions, as biomass is used more efficiently or replaced by more modern energy forms. Large hydropower represents 3\% and is growing modestly, primarily in developing countries. New renewable represents $2.4 \%$ and are growing very rapidly in developed 
countries and in some developing countries. Main renewable energy sources and their usage forms are given in Table 1 [4-15].

Table 1: Main Renewable Energy Sources and their Usage Form

\begin{tabular}{|c|l|l|}
\hline S.No. & Energy Source & \multicolumn{1}{c|}{ Energy Conversion and Usage Options } \\
\hline 1. & Solar & Solar dryers, solar cookers, solar home system \\
\hline 2. & Direct solar & Thermal power generation, photovoltaic, water Heaters, air heater \\
\hline 3. & Tidal & Tidal stream, barrage \\
\hline 4. & Wind & Windmills, water pumps, power generation, wind generators, \\
\hline 5. & Hydropower & Power generation \\
\hline 6. & Wave & Numerous designs \\
\hline 7. & Modern biomass & Pyrolysis, gasification, digestion, heat and power generation, \\
\hline 8. & Geothermal & Hydrothermal, hot dry rock, urban heating, power generation, \\
\hline
\end{tabular}

\section{SMALL HYDRO POWER}

Hydropower systems are dependent on very specific combinations of geography, demand and land-use issues, and many of the current opportunities for hydropower are in small hydro. The definition of small hydro varies, but typically pertains to hydro projects generating up to $10 \mathrm{MW}$. A maximum of $10 \mathrm{MW}$ is the most widely accepted value worldwide. Small hydro installations were cheaper to run, but expensive to build. The concept is changing now with smaller, lighter and high-speed turbine equipment, low cost electronic speed and load control systems and inexpensive plastic penstock. Small-scale hydropower is one of the most cost-effective and reliable energy technologies to be considered for providing clean electricity generation [1,7-12].

Capital investment in SHP has still been higher than in a diesel generating system of comparable capacity, the long life and low operating costs, which make it an attractive option for many applications. Small hydroelectric system provides clean, cheap electricity for local applications. Small-scale system captures the energy of flowing water and converts it to electricity. Although the potential of the small hydroelectric system depends on the availability of water flow, where the resource exists, it can provide cheap, clean and reliable electricity. Figure 1 shows a schematic typical small hydro power plant scheme. Water is taken from the river by diverting it through an intake at a weir. The weir is a manmade barrier across the river, which maintains a continuous flow through the intake. Before descending to the turbine, the water passes through a settling tank or forebay, in which the water is slowed down sufficiently for suspended particles to settle out. The freebie is usually protected by a rack of metal bars (a trash rack), which filters out waterborne debris which might damage the turbine such as stones, timber, or man-made litter [1-12]. 


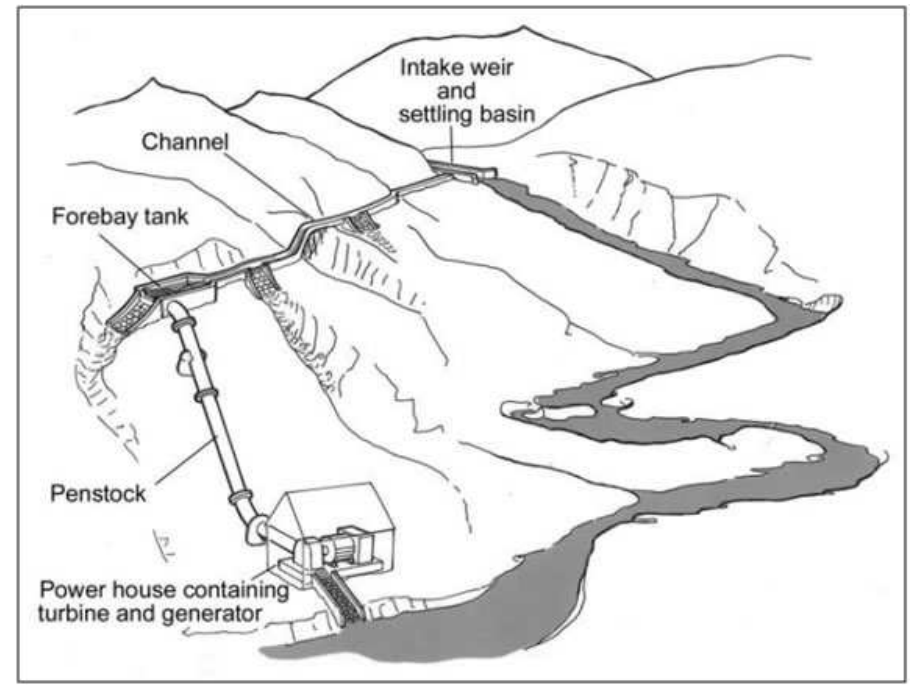

Figure 1: Schematic of a Small Hydro Power Plant Scheme

Hydro power has been considered as a standout among the most dependable and flexible type of renewable energy source, which can satisfy both base and pinnacle request. Around $1.31 \mathrm{TW}$ of hydro power has been created overall, which is $16.3 \%$ of the aggregate request of power. As per a report in 2008 , in view of the structure of renewable, vitality assets saddled indicate $86.31 \%$ of the renewable energy is created by hydropower plant [3]. Hydro turbines are heart of hydro power plants and working of hydro power plants primarily rely upon turbine effectiveness. The variable, which influences the execution of hydro turbines is residue disintegration. Sediment disintegration is for the most part considered as steady evacuation of material created by disfigurement and cutting activity [6-9].

The fundamental driver of disintegration in hydro turbine parts is the mix of high grouping of residue with a higher rate of quartz substance in water, which is to a great degree hard material. Erosion in hydro turbines for the most part rely on upon different variables like sediment size, sediment concentration, working hours, stream velocity, jet diameter, residue shape and nozzle angle [10-12]. In case of impulse turbine buckets, nozzle, blades and needle are affected due to silt erosion, and in case of reaction turbines, runner blades, face plates and guide vanes are prone due to sediment erosion. Because of sediment disintegration stream design changes, loss in effectiveness and vibration delivered, lastly breakdown of hydro turbine happen. Various research have been attempted to foresee the conduct and to decrease the impact of disintegration in hydro turbines, because of sediment [13-20].

Bain et.al [21] built up a relationship to explore the disintegration rate by gathering broad data from a bench scale test rig. The connection can be spoken to in the given shape as,

$$
W=K V V^{\beta} d^{\gamma} C^{\varphi}
$$

Where, $\mathrm{W}$ is erosion rate, $\mathrm{V}$ is the velocity of the particle, $\mathrm{d}$ is particle size, $\mathrm{C}$ is solid concentration, and $\mathrm{K}, \beta, \gamma$ and $\varphi$ are constants, whose values depend on the properties of the rodent as well as the target material. Khurana et al. [22] have conducted a research work on Turgo impulse turbine blade.

Tsuguo [23] established a correlation of basic parameters, which are responsible for the erosion of turbines based on erosion data of 18 hydropower plants of 8 years. He proposed following relation to estimate erosion in turbines.

$$
W=\beta \cdot C^{x} \cdot a^{y} \cdot k_{1} \cdot k_{2} \cdot k_{3} \cdot V^{m}[\mathrm{~mm} / \mathrm{year}]
$$


Where, $\mathrm{W}$ is loss of thickness per unit time, $\beta$ is turbine coefficient at eroded part, $\mathrm{V}$ is relative flow velocity. The term $a$ is coefficient of average grain size on the basis of unit value for grain size $0.05 \mathrm{~mm}$. The terms $k_{1}$ and $k_{2}$ are coefficient of the shape and hardness of sand particles and $\mathrm{k}_{3}$ is abrasion resistant coefficient of material. The $\mathrm{x}$, $\mathrm{y}$ are exponent values for concentration and size coefficient, respectively. Naidu [24] revealed a review that India is confronting the issue of sediment in very nearly 22 substantial hydropower stations. These power stations have been arranged into three classifications, in view of level of harm: impressive harm, which needs unmistakable endeavors and assets inside 15-20 years; broadly high harm, which require changes in at regular intervals; and serious harm which requires repair each year.

Thapa et al. [25] examined the impact of suspended residue in hydro power ventures in view of a contextual analysis of 60MW Khimti hydro power plant. Because of nearness of high measures of residue, the hydro power plant was composed with settling bowls to screen $85 \%$ of all particles with a width of $0.13 \mathrm{~mm}$, and $95 \%$ of all particles with a distance across of $0.20 \mathrm{~mm}$. The plant was dispatched in July 2000 and the harm to the turbine segments was explored in July 2003. The agents watched that a lot of disintegration showed up in the turbine bucket and needles. Chitrakar et al. [26] describes the simultaneous nature of combining effect, which contributes to vibration, losses, fatigue problems and failure of Francis turbines. They have also discussed to minimize the combine effect by controlling the erosion or secondary flow in the turbine. Other various studies [27-35] on turbine blades, erosive bear rate turbine bucket were done by providing to analyze the impact of different site parameters and working parameters such as silt size, silt concentration, stream velocity and working time. Khurana et al. [36] have conducted a research work on Turgo impulse turbine blade, using Finite element Analysis software. They have developed models of Turgo blade on ANSYS software. They have used ANSYS software for stress analysis and deformation produced inside the turbo blade. Table 2. Shows the developed correlations for erosion wear by various investigators

Table 2: Developed Correlations for Erosion Wear by Various Investigators

\begin{tabular}{|c|c|c|c|}
\hline Investigators & Correlations & $\begin{array}{l}\text { Type of } \\
\text { Turbine }\end{array}$ & Range of Parameters \\
\hline Khurana \&Varun [11] & $\begin{array}{l}W \\
=9.41 \\
\times 10^{4} D^{0.187} S^{-3.137\{(\ln (s) 2\}} C^{-3.961} e^{0.277\{(\ln (c)) 2\}} t^{0.540}\end{array}$ & $\begin{array}{l}\text { Turgo } \\
\text { Impulse }\end{array}$ & $\begin{array}{l}\mathrm{C}=1000-8000 \mathrm{ppm}, \mathrm{S}= \\
100-370 \mu \mathrm{m}, \mathrm{V}=28.805 \\
\mathrm{~m} / \mathrm{s}, \mathrm{D}=7.2-12.5 \mathrm{~mm}\end{array}$ \\
\hline Naidu [17] & $W=S_{1} S_{2} S_{3} S_{4} M^{r} v^{x}$ & $\begin{array}{l}\text { Pelton, } \\
\text { Francis }\end{array}$ & $\begin{array}{l}\text { The value for the } \\
\text { exponent } X=1.5 \text { for } \\
\text { Pelton buckets, } 2.5 \text { for } \\
\text { Pelton nozzle, } 3 \text { for } \\
\text { Francis runner, } 2.5 \text { for } \\
\text { guide vanes and pivot } \\
\text { ring liner }\end{array}$ \\
\hline Bajracharya et al. [19] & Erosion wear rate $\propto$ asize $e^{b}$ & Pelton & $\begin{array}{l}\text { Erosive wear rate in } \\
\mathrm{kg} / \text { year } \mathrm{a}=351.35, \mathrm{~b}= \\
1.4976 \text { for quartz content } \\
\text { of } 38 \% \text {; } \mathrm{a}=1199.8, \mathrm{~b}= \\
1.8025 \text { for quartz content } \\
\text { of } 60 \% \text {; } \mathrm{a}=1482.1, \mathrm{~b}= \\
1.8125 \text { for quartz content } \\
\text { of } 80 \%\end{array}$ \\
\hline Khurana et al. [22] & $W=1.976 \times 10^{-10} S^{0.118} C^{0.967} V^{1.368} t^{1.117}$ & $\begin{array}{l}\text { Turgo } \\
\text { Impulse }\end{array}$ & $\begin{array}{l}\mathrm{C}=3000-12,000 \mathrm{ppm}, \mathrm{S} \\
=50-390 \mu \mathrm{m}, \mathrm{V}=26.81- \\
28.81 \mathrm{~m} / \mathrm{s}\end{array}$ \\
\hline $\begin{array}{l}\text { Thapa, and } \\
\text { Dahlhaug [27] }\end{array}$ & $E_{r}=C \cdot K_{\text {hardness }} \cdot K_{\text {shape }} \cdot K_{m} \cdot K_{f} \cdot a \cdot \operatorname{size}^{b}[\mathrm{~mm} / y r]$ & Francis & $\begin{array}{l}\mathrm{C}=0.5 \mathrm{~kg} / \mathrm{m}^{3}, \mathrm{~K}_{\text {size }}= \\
0.025 \mathrm{~mm}, \mathrm{~K}_{\text {shape }}=1, \\
\mathrm{~K}_{\text {hardness }}=0.83, \mathrm{~K}_{\mathrm{m}}=1\end{array}$ \\
\hline
\end{tabular}




\begin{tabular}{|c|c|c|c|}
\hline \multicolumn{4}{|c|}{ Table 2: Contd., } \\
\hline Thapa et al. [28] & $\eta_{r}=a \cdot \operatorname{erosion}^{b}[\% / y r]$ & Francis & $\begin{array}{l}\mathrm{C}=0.5 \mathrm{~kg} / \mathrm{m}^{3}, \mathrm{~K}_{\text {size }}= \\
0.025 \mathrm{~mm}, \mathrm{~K}_{\text {shape }}=1, \\
\mathrm{~K}_{\text {hardness }}=0.83, \mathrm{~K}_{\mathrm{m}}=1\end{array}$ \\
\hline Krause and Grein [29] & $\delta=P Q C V^{3.4} f\left(D_{50}\right)$ & Pelton & $\begin{array}{l}\text { Particle size }=40-70 \mu \mathrm{m} \text {, } \\
\text { sand containing } 99 \% \\
\text { quartz }\end{array}$ \\
\hline $\begin{array}{l}\text { Gupta, Singh, and } \\
\text { Seshadri [30] }\end{array}$ & $E_{w}=K V^{\beta} d^{\gamma} C^{\varphi} f(\alpha)$ & ------ & $\begin{array}{l}\mathrm{V}=3.92-8.06 \mathrm{~m} / \mathrm{s}, \text { size }= \\
448.5,223.5,112.5 \text { and } \\
37.5 \mu \mathrm{m}, \mathrm{C}=15,25,35 \\
\text { and } 45(\% \text { by wt })\end{array}$ \\
\hline Padhy and Saini [31] & $W=4.02 \times 10^{-12}(s)^{0.0567}(c)^{1.2267}(v)^{3.79} t$ & Pelton & $\begin{array}{l}\mathrm{C}=5000-10,000 \mathrm{ppm}, \\
\text { size }=90-355 \mu \mathrm{m}, \mathrm{V}= \\
26.61-29.75 \mathrm{~m} / \mathrm{s}\end{array}$ \\
\hline
\end{tabular}

\section{EXPERIMENTAL DETAILS}

Another trial set up has been composed and created by the Pelton turbine model design for $1 \mathrm{~kW}$ control yield, as appeared in Figure 2. The runner of a Pelton turbine having pitch circle diameter $145 \mathrm{~mm}$, nozzle diameter $12 \mathrm{~mm}$ and having 20 quantities of buckets has been utilized for the exploratory review. The heaviness of every basin is around 115 gm. The model of every bucket and runner was made on AutoCAD and CREO version 2016, as appeared in Figure 3. To get the disintegration in limited ability to focus time, turbine buckets were made of Aluminum. In this test work, two tanks were made $(650 \mathrm{~mm} \times 520 \mathrm{~mm} \times 800 \mathrm{~mm})$. The principal tank was utilized to store water and to flow, sediment water blend to the runner of Pelton turbine of various residues focuses. The second tank was utilized to quantify the release, by utilizing rectangular notch. Amid test work a stirrer was utilized constantly, in order to supply a uniform blend of sediment water to turbine runner. A penstock pipe having $70 \mathrm{~mm}$ external width and $3 \mathrm{~mm}$ thickness was utilized for providing water to the turbine runner. A monoblock having $40 \mathrm{~m}$ evaluated head and release limit of $9 l / s$ was utilized to make hydro potential. A computerized weight transducer of Yokogawa makes having scope of $0.5 \mathrm{kPa}$ to $14 \mathrm{MPa}$ and having exactness $\pm 0.065 \%$ was fitted to the penstock pipe to quantify the net heat at bay of Pelton turbine. A generator was straight forwardly coupled to the turbine shaft. Electric knobs of various wattages were utilized as resistive load. The electric load was measured to decide the yield of the turbine. The weight reduction of Pelton basins was measured previously, then after the fact, experimentation with the assistance of electronic weight adjust having a minimum tally of $0.1 \mathrm{mg}$. Distinctive sorts of sifters of 90, 150, 300 and 450 microns were utilized, so that the reviewing of sediment should be possible. 


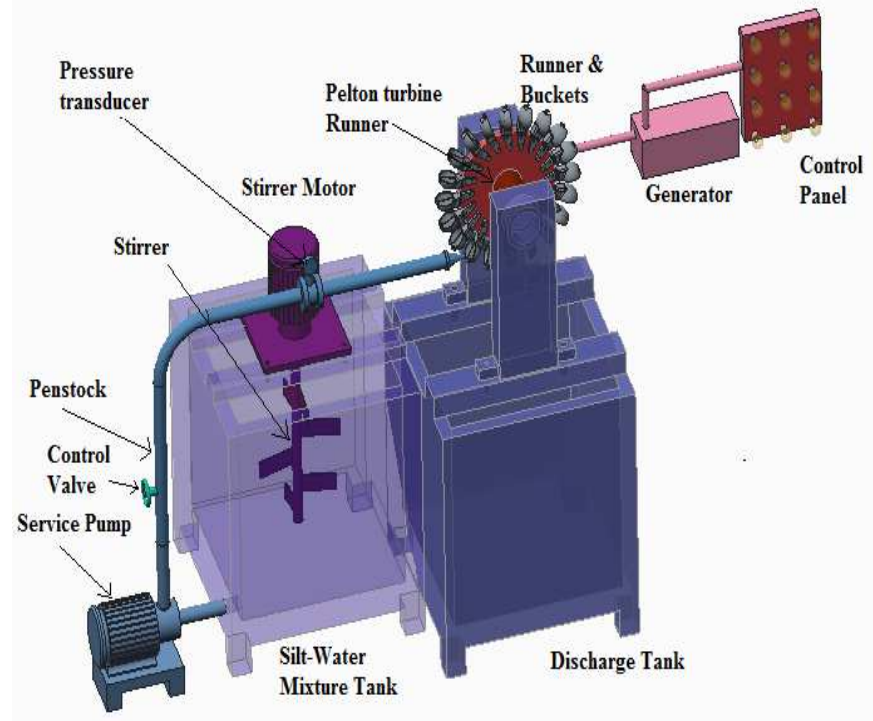

Figure 2: Schematic of Experimental Setup

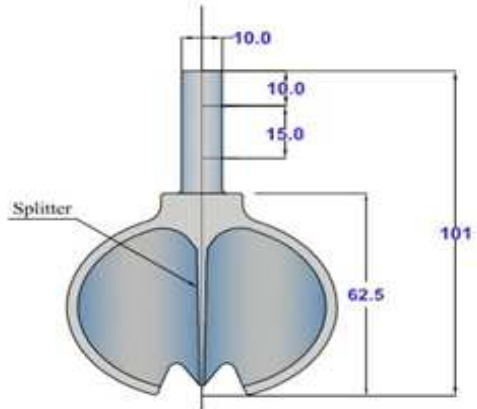

(A)

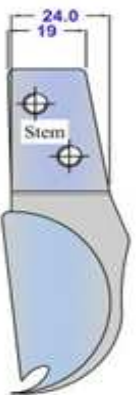

(B)
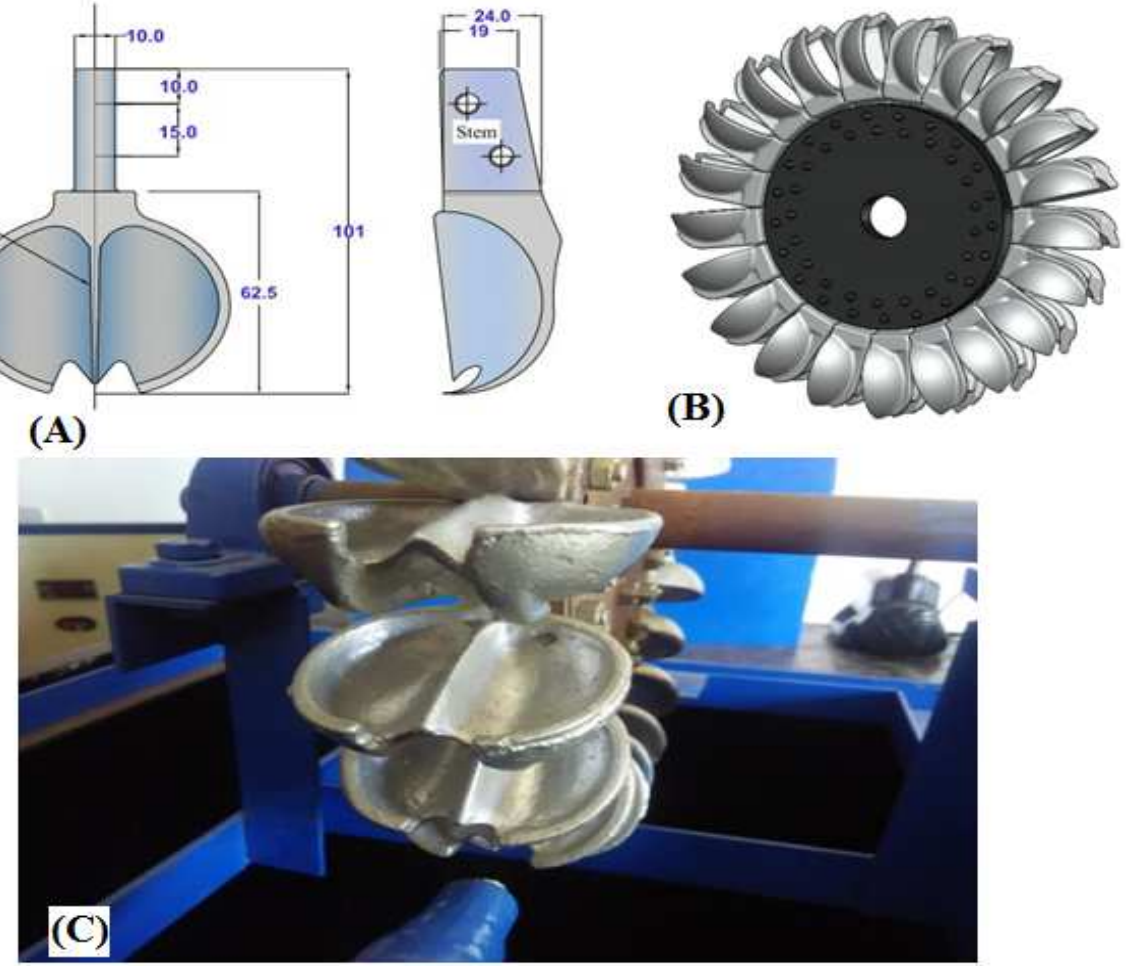

Figure 3: Schematic of Pelton Turbine Blades and Runner and Photographic View of Pelton Turbine Bucket

\section{EXPERIMENTAL PROCEDURE}

Before beginning the investigation, a trial test was directed to check the best possible working of the entire setup. Legitimate work of the considerable number of instruments was additionally confirmed. At the first administration, pump drew water from the capacity tank and provided it to the turbine. Water from the turbine was permitted to move through 
second, fitted with the rectangular score for release estimation. The height of water over the crest of the notch was recorded by a pointer gauge and the release of the pump relating to every head was resolved. The figuring of release will be made based on the height of water (h) streaming over the peak.

To examine the impact of residue disintegration on containers of Pelton turbine, silty water of known focus was set up in the principal tank. For providing a uniform blend of sediment and water ceaselessly to turbine, a stirrer was tuned with the assistance of engine.

Amid, tests head and stream were kept steady. One arrangement of readings was taken at four estimations of time interim of $2 \mathrm{~h}$ by keeping one parameter as fix and other parameter as variable. To assess disintegration qualities, an aggregate 192 arrangements of the readings were recorded by taking distinctive estimations of residue size four arrangements of trials, also for sediment focus, four arrangements of examinations, and for stream speed, three arrangements of tests were directed. To explore the disintegration in containers, they were destroyed after, at regular intervals of investigation. An advanced adjust of Tapson make with traverse go from $10 \mathrm{~g}$ to $210 \mathrm{~g}$ and least count of 0.1 mg were utilized to gauge loss of weight. Be that as it may, because, of course, of silty water to turbine runner, the impeller of the pump got disintegrated after a certain time of operation, so, the impeller was supplanted with new impeller.

\section{Range of Parameters}

In this test, work residue measure, sediment focus, stream speed and working hours were researched parameters. For this, the specimen of sediment was gathered from camera lake, Chamba (HP, India), in which the sediment concentration amid storm season was around 20000 p.m., and the normal quartz substance was observed to be around $80 \%$. The residue was dried in the daylight for 3-4 days and sifters of various sizes were utilized to strainer the sand, before blending with water. The scope of parameters utilized in the present review appears in Table 3.

Table 3: Range of Parameters

\begin{tabular}{|c|l|c|}
\hline S.No. & \multicolumn{1}{|c|}{ Parameters } & Range \\
\hline 1 & Silt size & $90,150,300,450 \mu \mathrm{m}$ \\
\hline 2 & Silt concentration & $2000,4000,6000,8000 \mathrm{ppm}$ \\
\hline 3 & Jet Velocity & $25.46,26.45,27.32 \mathrm{~m} / \mathrm{s}$ \\
\hline 4 & Operating hours & $8 \mathrm{~h}$ \\
\hline
\end{tabular}

\section{UNCERTAINTY ANALYSIS}

Uncertainty in experimental measurements has been carried out. Let a set of measurement is made and the uncertainty in each measurement may be expressed. These measurements are then used to calculate some output (result) of experiments. The result $(\mathrm{R})$ is a given function of the independent variables $\mathrm{x}_{1}, \mathrm{x}_{2}, \mathrm{x}_{3} \ldots \mathrm{x}_{\mathrm{n}}$. Hence

$$
R=R\left(x_{1}, x_{2}, \ldots \ldots, x_{n}\right)
$$

Let $\mathrm{W}_{\mathrm{R}}$ be the uncertainty in the result and $\mathrm{W}_{1}, \mathrm{~W}_{2}, \mathrm{~W}_{3}, \ldots \ldots \ldots, \mathrm{W}_{\mathrm{n}}$ be the uncertainties in the independent variables. The resultant uncertainty $\left(\mathrm{W}_{\mathrm{R}}\right)$ is calculated as;

$$
W_{R}=\left[\left(\frac{\partial R}{\partial x_{1}} W_{1}\right)^{2}+\left(\frac{\partial R}{\partial x_{2}} W_{2}\right)^{2}+\ldots \ldots \ldots \ldots . . .+\left(\frac{\partial R}{\partial x_{n}} W_{n}\right)^{2}\right]
$$

Uncertainty calculation for Silt size $(S)$ 
$S=S_{1}-S_{2}$

Particular size range

$$
\begin{aligned}
& \frac{W_{S}}{S}=\frac{\left[\left(W_{S_{1}}^{2}\right)+\left(W_{S_{2}}^{2}\right)\right]^{0.5}}{S} \\
& \frac{W_{S}}{S}=\frac{\left[\left(1^{2}\right)+\left(1^{2}\right)\right]^{0.5}}{90}=0.0157=1.57 \%
\end{aligned}
$$

The maximum possible measurement errors in the values of major parameters are given below in Table 4 .

Table 4: Uncertainty Analysis of Major Parameters

\begin{tabular}{|l|l|c|c|}
\hline S.No. & \multicolumn{1}{|c|}{ Parameters } & Range & Uncertainty \\
\hline 1 & Silt size & $90,150,300,450 \mu \mathrm{m}$ & $1.57 \%$ \\
\hline 2 & Silt concentration & $\begin{array}{c}2000,4000,6000, \\
8000 \mathrm{ppm}\end{array}$ & $0.25 \%$ \\
\hline 3 & Weight Loss & $115 \mathrm{~g}$ & $0.69 \%$ \\
\hline 4 & Operating hours & $8 \mathrm{~h}$ & $1.18 \%$ \\
\hline 5 & Pressure & $0.5 \mathrm{kPa}$ to $14 \mathrm{MPa}$ & $\pm 0.065 \%$ \\
\hline 6 & Discharge & $\mathrm{H}=45-90 \mathrm{~mm}$ & $1.68 \%$ \\
\hline
\end{tabular}

\section{RESULTS AND DISCUSSIONS}

\section{Silt Concentration}

In light of test examination, the graphs were plotted to talk about the impact of sediment concentration on the wear rate on the containers of Pelton runner, as appearing in Figure 4. These graphs are created under a static estimation of stream speed of $25.464 \mathrm{~m} / \mathrm{s}$ for various sediment concentrations. In this test work, weight reduction esteem for buckets were considered for further investigation, as each of the 20 basins were practically indistinguishable fit as a shape and size.

The variety of standardized wear (loss of weight/original weight) of buckets with working time for various sizes of sediment particles has been appeared in Figure 4. The graph plotted demonstrates a straight relationship between standardized wear and working time. It is watched that, with the expansion in sediment fixation, the erosive wear rate likewise increases for a given size range. Figure 5 demonstrates the variety of erosive wear rate with sediment focus for various sizes. 

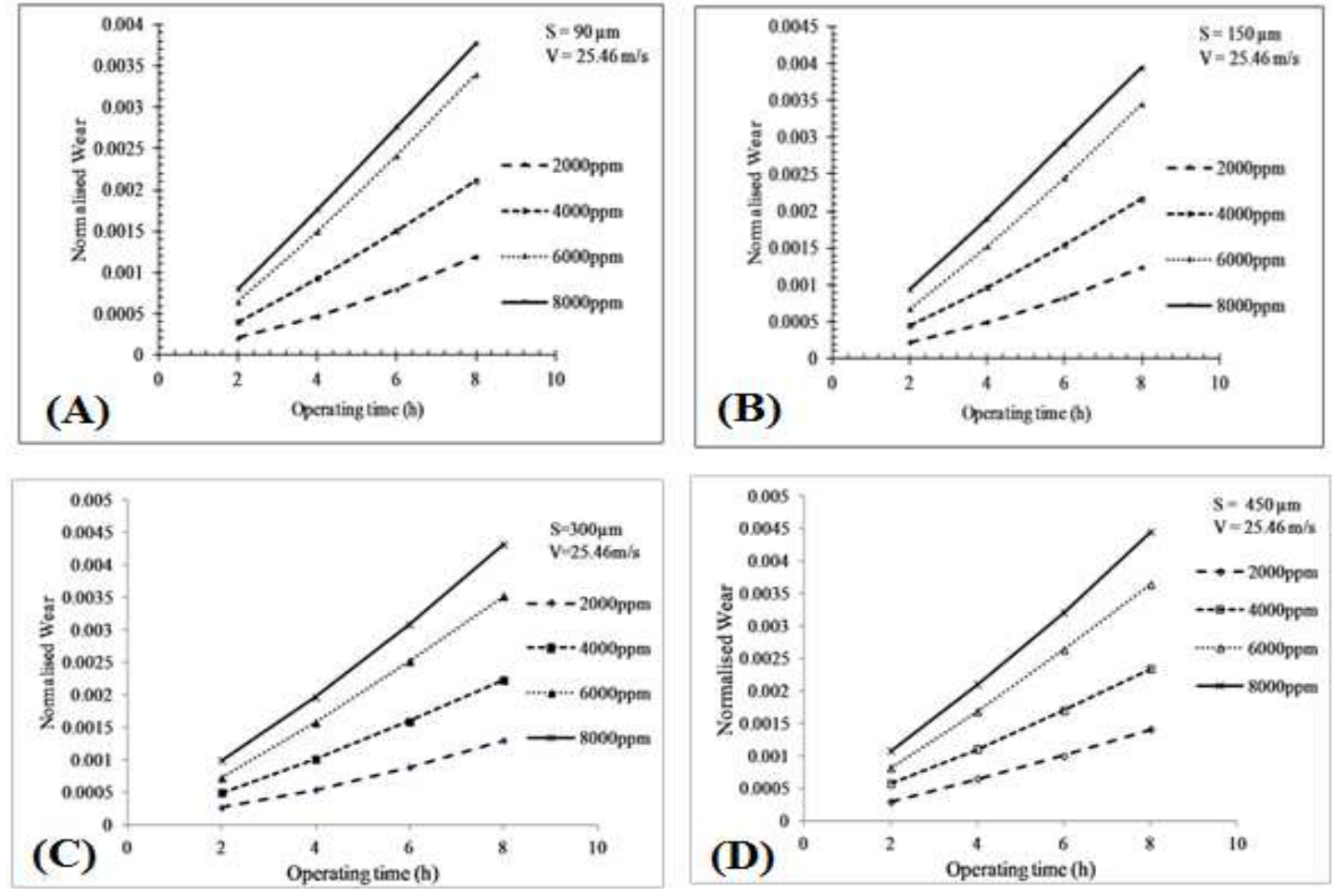

Figure 4: Effect of Silt Concentration on Normalized Wear for the Size Range (A) $90 \mu \mathrm{m}$ (B) $150 \mu \mathrm{m}$ (C) $300 \mu \mathrm{m}$ (D) $450 \mu \mathrm{m}$

\section{Silt Size}

To watch the impact of sediment size on the disintegration rate of various buckets of the runner, distinctive size of residue were considered while different components like sediment concentration, working time and stream speed stayed steady. From Figure 5, variety of mean particle size of standardized wear for various sediment concentrations for $8 \mathrm{~h}$ of operation can be anticipated. From the figure, it can be watched that with the ascent in the extent of the particle erosive wear rises on the grounds, a more noteworthy size particle has high energy of impact. An indistinguishable perception was broke down by different observers. [24, 27-29].

\section{Stream Velocity}

Various examinations were directed at different heads to watch the impact of stream velocity on erosive wear rate. It has been seen from literature review [29-31] that with ascend in stream velocity, the erosive wear raises relatively as uncovered in Figure 6. Subsequent examinations were completed for a given molecule size and focus. It can be seen that the erosive wear rate takes following the power law, with respect to stream velocity (i.e. $\mathrm{W} \propto \mathrm{V}^{\mathrm{n}}$ ). The estimation of $n$ for this review is 1.94, which can be seen from the relationship in Figure 6. 

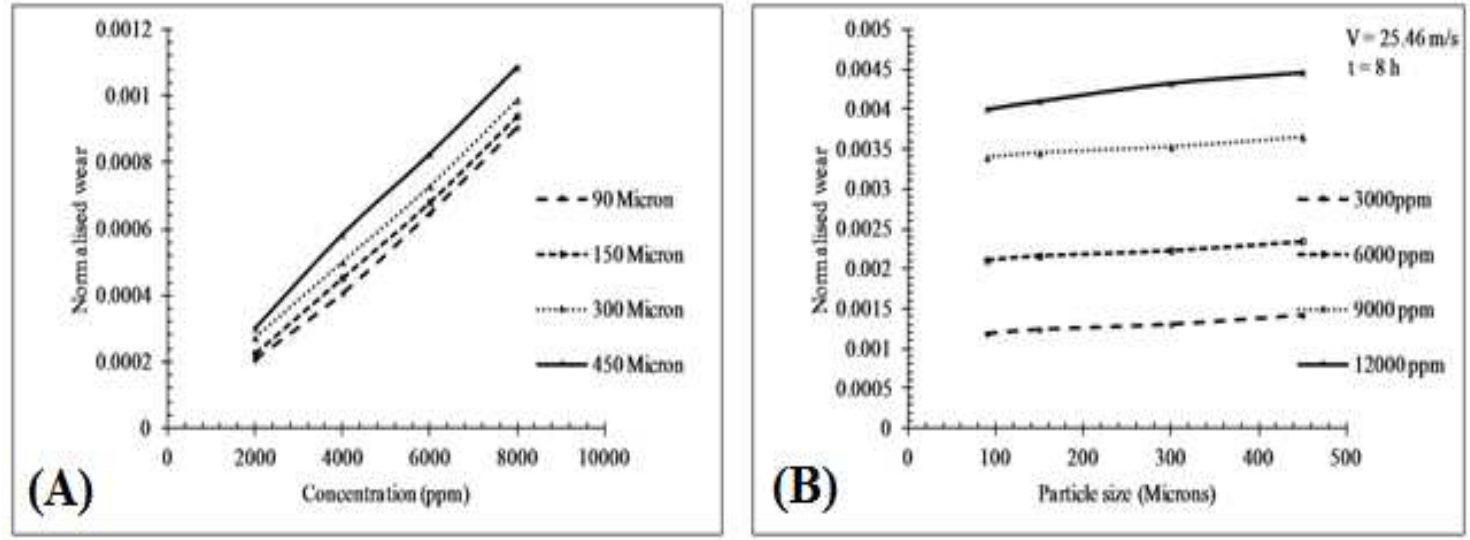

Figure 5: (A) Effect of Silt Concentration on Normalized Wear Normalized Wear for Various Concentrations (B) Effect of Silt Size on for Various Silt Sizes
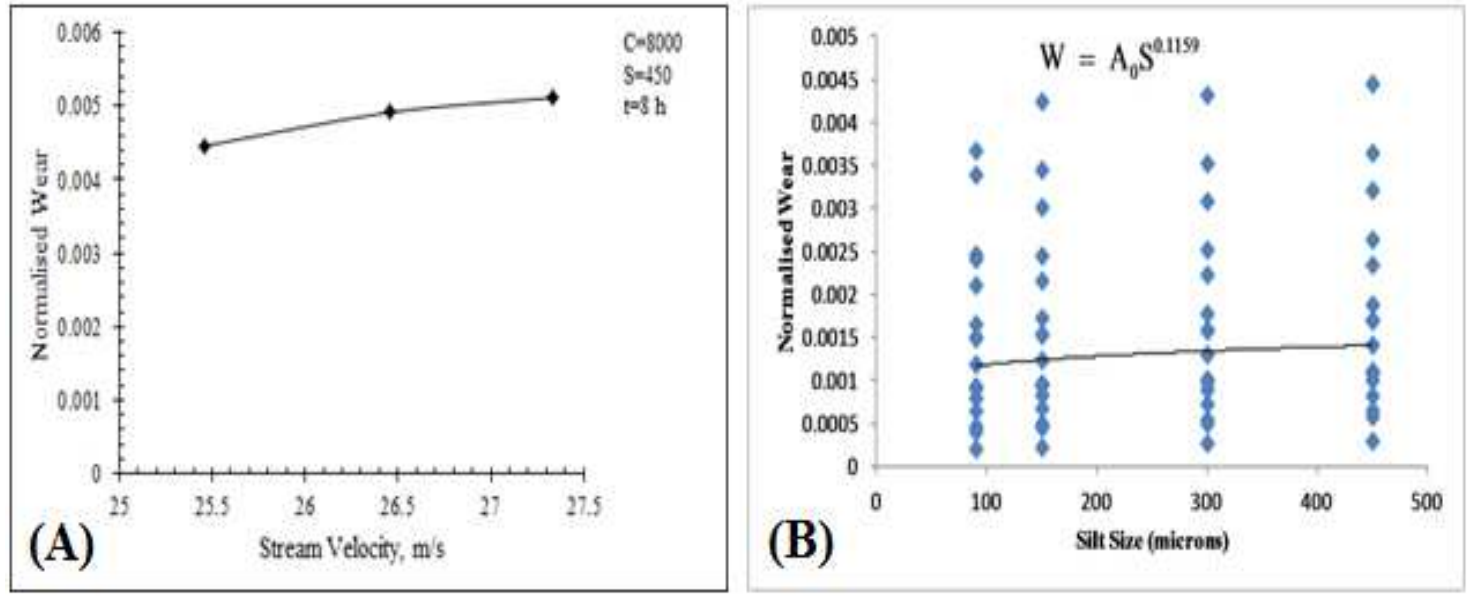

Figure 6: (A) Effect of Stream Velocity on Wear of Turbine Bucket (B) Plot of Normalized Wear on Bucket Due to Silt Size

\section{Finite Element Method}

In the present work, modeling of runners and blades were carried out on ANSYS software. The stress analysis is carried out in Ansys work bench. The main purpose of using Ansys is to find out position of stress and deformation acting on Pelton bucket. The basic concept used in finite element method is that, a body or the structure may be divided into smaller elements of finite dimensions, called finite elements. The original body or the structure is then considered as an assemblage of these elements connected at a finite number of joints, called nodes or nodal points. The properties of the elements are formulated and combined to obtain the solution for the entire body or structure. The finite element method, sometimes referred to as finite element analysis, according to a computational technique used to obtain approximate solutions of boundary value problems in engineering. In the early years, applications were performed using mainframe computers, which at the time, were considered to be very powerful, high- speed tools for use in engineering analysis. During the 1960s, the finite element software code NASTRAN was developed in conjunction with the space exploration programmed in the United States. NASTRAN was the first finite element software code. Among these, ANSYS \& ALGOR are also used in computerized environment. The Bucket of Pelton turbine was modeled in Solid Works software. The designs of blades were converted in to IGES format, and they were imported in ANSYS software (Version 15.0) for 
meshing. Physical parameters and mechanical properties used in the present analysis as shown in Table 5.

The Four Tasks Involved in the Analysis Process Were Given as:

- Modeling of the geometry on solid works software.

- $\quad$ Meshing the geometry on Ansys.

- Solving the equations on software.

- $\quad$ Post processing to obtain the results.

Table 5: Physical Parameters and Mechanical Properties

\begin{tabular}{|c|l|c|}
\hline S.No. & \multicolumn{1}{|c|}{ Parameters } & Values \\
\hline 1. & Nodes & 5567 \\
\hline 2. & Elements & 2851 \\
\hline 3. & Density & $8.3 \mathrm{e}-006 \mathrm{~kg} \mathrm{~mm}^{\wedge}-3$ \\
\hline 4. & Compressive yield strength & $280(\mathrm{MPa})$ \\
\hline 5. & Tensile yield strength & $430(\mathrm{MPa})$ \\
\hline 6. & Reference Temperature & $22^{\circ} \mathrm{C}$ \\
\hline 7. & Poisson's Ratio & 0.34 \\
\hline
\end{tabular}

After experimentation, it was watched that the pattern of erosion was indistinguishable in every one of the buckets. In Pelton turbine buckets, extraordinary disintegration was started along the profundity and at the score of the bucket. The splitter zone was additionally antagonistically influenced, because of disintegration as appeared in the pictorial perspective of one of the basins in Figure 7 and CFD domain as shown in Figure 8. The impacts of residue parameters and working parameters of standardized wear rate are talked about as takes after. Figure 9 shows the equivalent elastic strain on Pelton bucket, equivalent stress on Pelton bucket and total deformation in Pelto bucket.

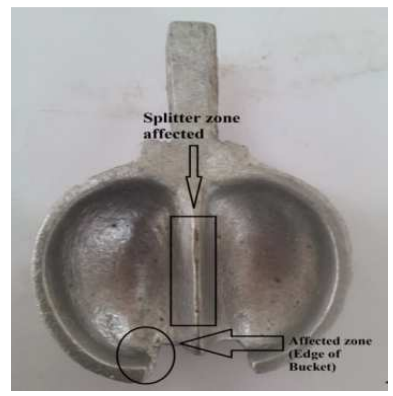

Figure 7: Surface Condition of Bucket after Experimentation
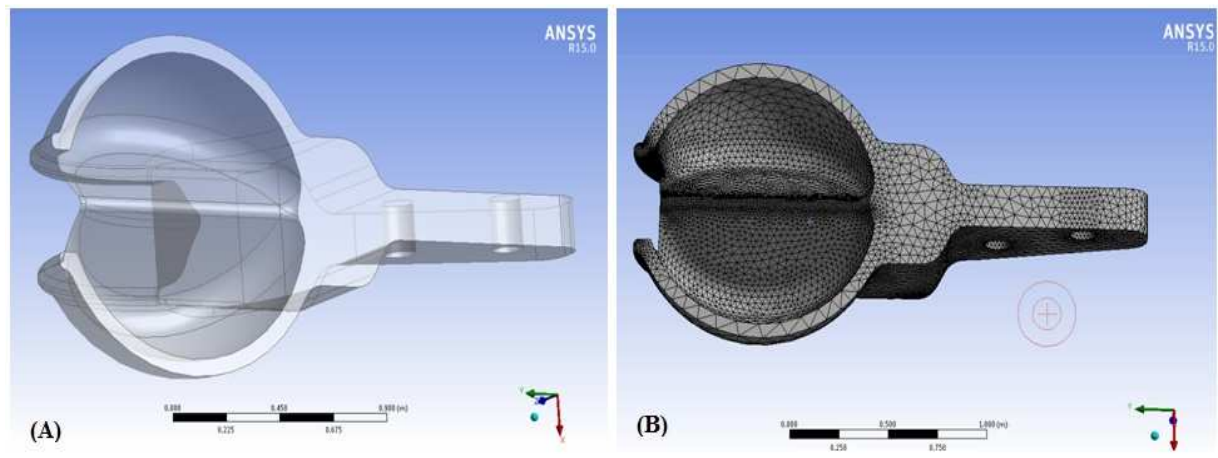

Figure 8 (A): CFD Domain for Analysis (B) Grid Generation 

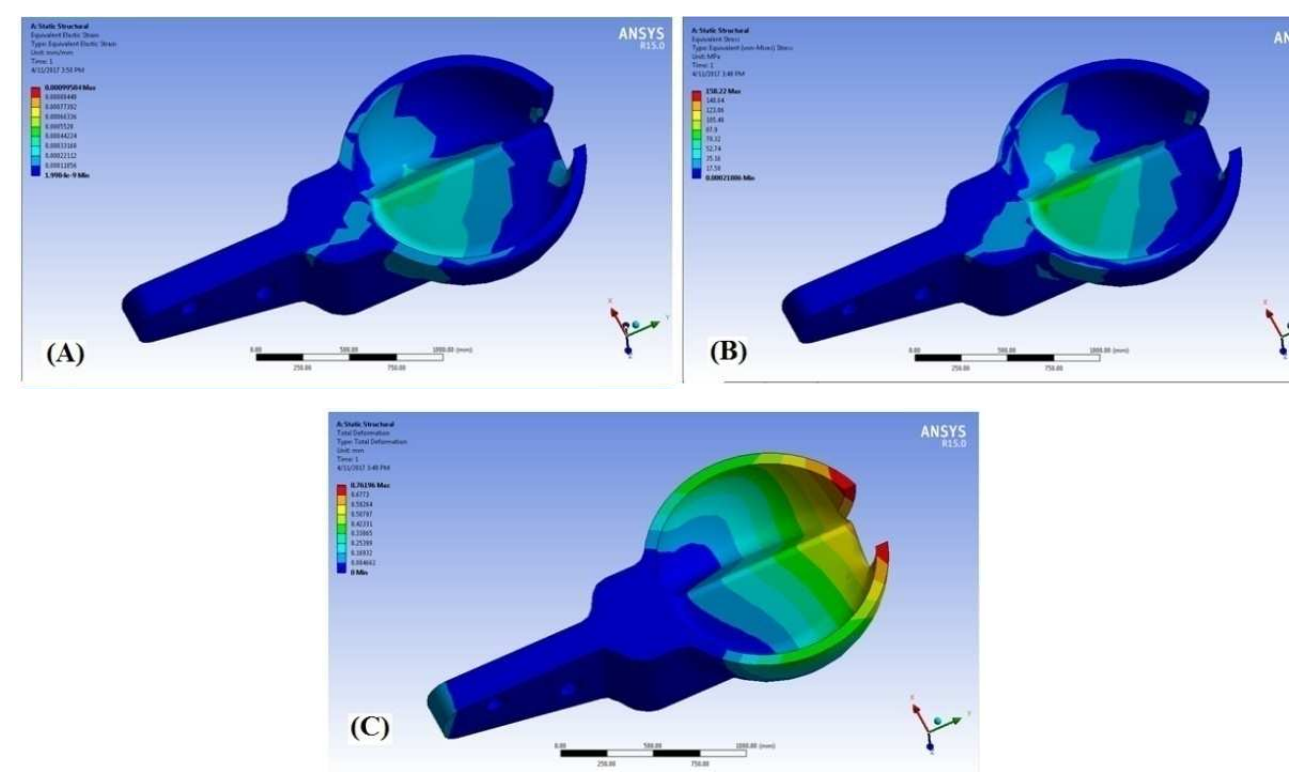

Figure 9: (A) Equivalent Elastic Strain on Pelton Bucket (B) Equivalent Stress on Pelton Bucket (C) Total Deformation in Pelto Bucket

\section{Correlation Developments for Wear Rate}

The erosive wear rate is strongly dependent on silt parameters (Silt size, Silt concentration) and Operating parameters (Stream Velocity, Operating hours of turbine). A correlation for the normalized wear as a function of silt and operating parameters has been developed from the experimental data.

The simplest equation for erosion is:

$$
\mathrm{W}=\mathrm{f}(\mathrm{S}, \mathrm{C}, \mathrm{V}, \mathrm{t})
$$

The values of the normalized wear, which we get from experimental work are used to find the effect of silt size on normalized wear, a plot for wear versus silt size was plotted and a power law line has been fitted to obtain the relation as shown in Figure 10.

$$
W=A_{0} S^{0.1159}
$$

Where, $S$ is silt size and $\mathrm{A}_{0}$ is a constant whose value is a function of other parameters, i.e. $C, V$ and $t$.

To observe the effect of $\mathrm{C}, \mathrm{V}$ and $\mathrm{t}, W / S^{0.1159}$ were plotted against $C$ (concentration), which is shown in Figure 10. A regression analysis to fit a straight line and a relation is obtained as below:

$$
\frac{W}{S^{0.1159}}=B_{0} C^{0.9096}
$$

In this relation, $C$ is the silt concentration and $B$ is a constant whose value depends upon two factors, i.e. $V$ and $t$. 

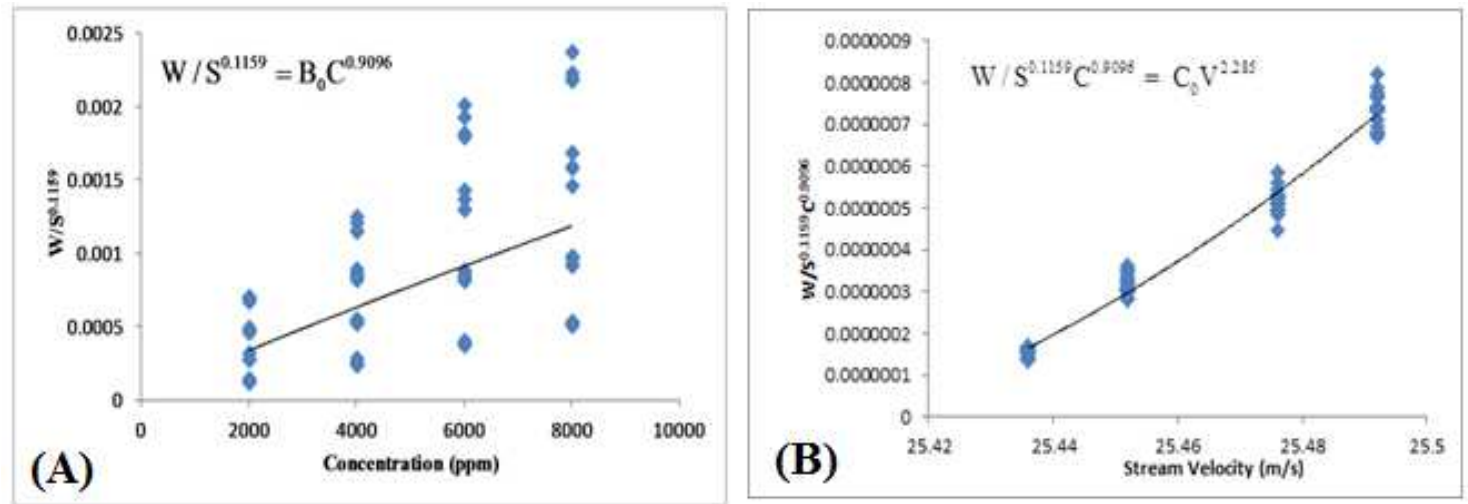

Figure 10: (A) Effect of Silt Concentration on Bucket Wear (B) Effect of Stream Velocity on Bucket Wear

Therefore, a graph was plotted between $W / S^{0.118} \cdot C^{0.967}$ versus $V$ (stream velocity), which is shown in Figure 11 . From the Figure 11, the following relation is obtained:

$$
\frac{W}{S^{0.1159} C^{0.9096}}=C_{0} V^{2.285}
$$

Where, $\mathrm{V}$ is the stream velocity and Cis a constant which depends upon time $t$. Therefore, to see the effect of operating time on wear rate, a graph was plotted between $\frac{W}{S^{0.1159} C^{0.9096} V^{2.285}}$ versus time (Figure 11) and the relation obtained is written as below:

$$
\frac{W}{S^{0.1159} C^{0.9096} V^{2.285}}=D_{0} t^{1.1317}
$$

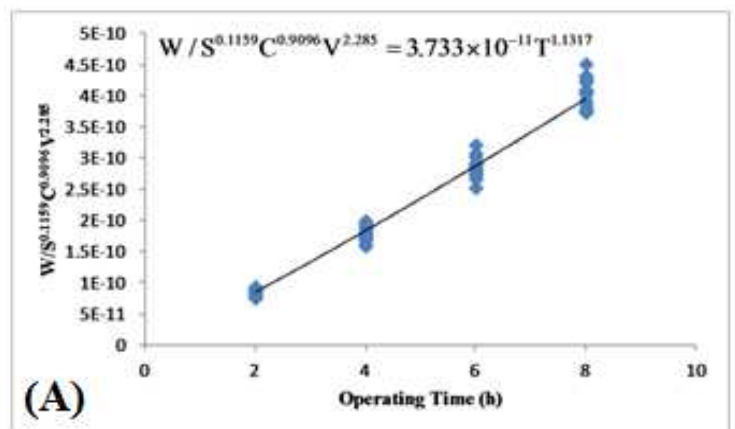

Figure 11: (A) Impact of Operating Time on Blade Wear and Predicted Wear of the Runner Bucket (B) Comparison of Actual Runner Bucket

By rearranging this relation, the final equation for normalized erosive wear rate can be written as follows:

$$
W=3.733 \times 10^{-11} S^{0.1159} C^{0.9096} V^{2.285} t^{1.1317}
$$

Figure 11 shows the comparison of the experimental data of erosive wear rate and the values obtained from the above stated correlation. A good agreement has been observed in the results. The average absolute percentage deviation between the experimental data and calculated values of erosive wear rate has been found to be within \pm 12 . $8 \%$. 


\section{CONCLUSIONS}

In this trial work, tests were directed for wear rate as a component of residue parameters and working parameters and from this trial work, we have presumed that:

- The erosive wear rate increases with the expansion in silt concentration, silt size, stream speed and working hours of turbine. According to perceptions, erosion was extraordinary at the profundity of the sharp edge and at the scores.

- The erosion on Pelton turbine bucket has been observed experimentally, as shown in Figure 3, and from this figure we can observe that maximum erosion occurs at splitter and the notch of the bucket. This result has been compared with Finite Element Analysis (Ansys software), which can be observed from Figure 14 that maximum deformation occurs at splitter and the notch of the bucket. The deformation produces inside the bucket, due to silty water.

- Investigation demonstrates the impact of various silt concentrations on the standardized wear for the size variation of $90 \mu \mathrm{m}$ to $450 \mu \mathrm{m}$. It is clear from the graphs that for the concentration range of $2000 \mathrm{ppm}$ to $8000 \mathrm{ppm}$, the normal standardized wear lies between $0.00078 \mathrm{~cm}$ to $0.00256 \mathrm{~cm}$ with steady speed of $25.46 \mathrm{~m} / \mathrm{s}$. As sediment size increases, standardized wear increases and likewise standardized wear is additionally inclined to fly speed.

- The examination likewise demonstrates that, sediment is a standout amongst the most dissolving components, and more prominent size sand particles have a high disintegration rate than smaller particles, streaming with water. The size assumes the key part, yet it could be according to shape, mineral substance and so on.

- By utilizing test comes about, a relationship was built up for wear rate as a component of silt concentration, silt size, stream velocity and working hours of turbine. The connection built up in this review can be utilized to foresee the standardized wear with \pm 12 . $8 \%$ error. The created relationship might be utilized to watch the disintegration in Pelton turbine buckets at the generation period of a turbine, at the assembling site, as a large portion of the power plants frequently close down because of the early disintegration of the material of turbine hardware.

\section{REFERENCES}

1. Pundir A, Kumar A. (2014) Technical feasibility study for power generation from a potential mini hydro site nearby Shoolini University, Advances Energy Research, 4, pp. 85-95.

2. Robin T, Suri ARS, Kumar S, Kumar A (2013) A Review of Integrated Renewable Energy System in Power Generation, International Journal of Mechanical and Production Engineering Research and Development, ISSN-22496890, 3(2013), pp. 79-88.

3. Kumar R, Pedgopu V, Kumar A, Thakur R, Pundir A (2013) CFD based analysis heat transfer and friction characteristics of broken multiple rib roughened solar air heater duct, International Journal of Mechanical and Production Engineering Research and Development, ISSN-22496890, 3, pp.165-172.

4. Kumar A, Kumar R, Maithani R, Chauhan R, Sethi M, Kumari A, Kumar S, Kumar S (2017) Correlation development for Nusselt number and friction factor of a multiple type V-pattern dimpled obstacles solar air passage, Renewable Energy, 109, pp. 461-479. 
5. Kumar S, Kothiyal AD, Bisht MSH, Kumar A (2017) Numerical analysis of thermal hydraulic performance $\mathrm{Al}_{2} \mathrm{O}_{3}-\mathrm{H}_{2} \mathrm{O}$ nanofluid flowing through a protrusion obstacles square mini channel, Case studies in Thermal Engineering, 9(2017), pp.108121.

6. Nishi Y, Inagaki T, Li Y, Omiya R and Fukutomi J (2014) Study on an undershoot cross flow water turbine. Journal of Thermal sciences 23 pp.239-245.

7. Edenhofer $O$, Madruga $R$ and Sokona $Y$ (2011) Renewable energy sources and climate change mitigation: special report of the intergovernmental panel on climate change. New York: Cambridge University Press.

8. Gohil P and Saini RP (2016) Coalesced effect of cavitation and silt erosion in hydro turbines - A review. Renewable and Sustainable Energy Reviews 33, 280-289.

9. Singh SC (1990) Operational Problems and Development of a New Runner for Silty Water. International Water Power and Dam Construction 4, pp.29-37.

10. Tong D (1981) Cavitation and Wear on Hydraulic Machines. International Water Power and Dam Construction 2, 30-40.

11. Khurana $S$ and Varun (2014) Effect of jet diameter on erosion of turgo impulse turbine runner. Journal of Mechanical Science and technology 28, pp.4539-4546.

12. Khurana S, Varun and Kumar A (2012) Effect of Nozzle Angle and Silt Parameters on Erosion and Performance of Turgo Impulse Turbine. International Journal of Thermal Technologies 2(4), pp. 204-208.

13. Chitrakar S, Neopane HP and Dahlhaug OG (2016) Study of simultaneous effects of secondary flow and sediment erosion in Francis turbines.Renewable energy 1-16.

14. Thapa, Dahlhaug and Thapa B (2008) Sediment erosion in hydro turbines and its effect on the flow around guide vanes of Francis turbine. Renewable and Sustainable Energy Reviews 12, pp. 1974-1987.

15. Padhy and Saini (2008) A review on silt erosion in hydro turbines. Renewable and Sustainable Energy Reviews 49, pp. 11001113.

16. Derakshan and Nourbakhsh (2008) Experimental study of characteristics curves of centrifugal pump working as turbines in different specific speeds. Experimental thermal and fluid Science 32, 800-807.

17. Naidu BSK (1997) Addressing the problems of silt Erosion at Hydro Plants. International Journal of Hydropower and Dams 3 , pp. $72-77$.

18. Padhy and Saini (2009) Effect of size and Concentration of Silt Particles on Erosion of Pelton Turbine Buckets. Energy 34, pp.1477-1483.

19. Bajracharya, Joshi, Saini and Dahlaug (2008) Sand erosion of Pelton Turbine nozzles and buckets: a case study of chilme hydropower plant. Wear 264, pp. 177-184.

20. Bitter JGA (1963) A Study of Erosion Phenomenon- Parts I and II. Wear 6, pp.169-190.

21. Bain and Bonnington (1970) The hydraulic transport of solids by pipeline. 1st ed. Oxford: Pergamon Press 13, pp.1-6.

22. Khurana, Varun and Kumar (2014) Effect of Silt Particles on erosion of Turgo impulse turbine blades. Ambient Energy 35, pp.155-162.

23. Tsuguo $N$ (1999) Estimation of repair cycle of turbine due to abrasion caused by suspended sand and determination of desilting basin capacity. In Proceedings of International Seminar on Sediment handling technique NHA, Kathmandu.

24. Naidu BSK (2004) Silting problem in hydro power plant \& their possible solutions. Delhi, India, NPTI. 
25. Thapa, Strestha, Dhakal and Thapa (2005) Problems of Nepalese hydropower projects due to suspended sediments. Aquatic Ecosystem Health Manage 8, pp. 251-257.

26. Sailesh Chitrakar, H.P Neopane and O.G Dahlhaug (2016) Study of simultaneous effects of secondary flow and sediment erosion in Francis turbines. Renewable energy pp.1-16.

27. Thapa BS, Thapa and Dahlhaug OG (2012) Empirical Modelling of Sediment Erosion in Francis Turbines. Energy 41, pp. 386- 391.

28. Padhy and Saini (2009) Effect of size and concentration of silt particles on erosion of Pelton Turbine Buckets. Energy 34, pp.1477-1483.

29. Krause and Grien (1996) Abrasion research and prevention. Hydropower Dams 3, pp. $72-7$.

30. Gupta, Singh and Seshadri (1995) Prediction of uneven wear in a slurry pipeline on the basis of measurements in a pot tester. Wear 184, pp. 69-78.

31. Padhy and Saini (2011) Study of Silt Erosion on Performance of a Pelton Turbine. Energy 36, pp. 141-147.

32. Goyal, Singh, Kumar and Sahni (2012) Slurry Erosion Behaviour of HVOF Sprayed WC-10Co-4 Cr and $\mathrm{Al}_{2} \mathrm{O}_{3}+13 \mathrm{TiO}_{2}$ Coatings on Turbine Steel. Wear 289, pp. 46-57.

33. Tsai W, Humphrey JAC, Cornet I and Levy AV (1981) Experimental Measurement of Accelerated Erosion in a Slurry Pot Tester. Wear 68, pp. 289-303.

34. Padhy and Saini (2008) A review on silt erosion in hydro turbines. Renewable and Sustainable Energy Reviews 12, pp.19741987.

35. Truscott (1972). Literature Survey of Abrasive Wear in Hydraulic Machinery. Wear. 20, pp.29-50.

36. Sourabh Khurana, Varun Goel and Anoop Kumar (2013) FEM Analysis of Turgo Impulse Turbine Blade, Walailak Journal of Science and Technology 10, pp.363-368. 